\title{
CRITICAL CONSIDERATIONS ON GENDER AND TOURISM: AN INTRODUCTION
}

\author{
DONNA CHAMBERS* AND TIJANA RAKIĆ† \\ *Department of Tourism, Hospitality and Events, University of Sunderland, Sunderland, UK \\ †School of Sport and Service Management, University of Brighton, Eastbourne, UK
}

\begin{abstract}
I imagine phallocentric reality to be the space and figures and motion which constitute the foreground, and the repetitive uneventful activities of women to constitute and maintain the background against which this foreground plays. It is essential to the maintenance of the foreground reality that nothing within it refer in any way to anything in the background and yet it depends absolutely upon the existence of this background. (Marilyn Frye, cited in Rose, 1993, p. 5)
\end{abstract}

The Global Gender Gap Report, produced by the World Economic Forum (WEF), seeks to quantify the extent of disparities based on gender in four key areas - health, education, economy, and politics - in over 100 countries across the globe. In its 11th edition published in 2016, the report concluded that no country in the world has fully closed its gender gap (WEF, 2016). This report is useful in so far as it provides quantitative indicators of the attainment gap between men and women in the four identified areas but it does not seek to unpack the very meaning of gender, nor does it seek to problematize the concept of "gender equality" as a necessary or desired state. Our inspiration for editing this special issue of Tourism, Culture \& Communication on gender and tourism stems from a recognition of what we would argue is the lack of sufficient coverage and theoretical depth to current discussions of gender within tourism research. It is of course commonly recognized that gender is a complex concept that cannot be understood based simply on deterministic biological differences between men and women. The World Health Organization (WHO) defines gender as socially constructed characteristics of both women and men (WHO, 2015). Gender is also culturally and politically contingent and is therefore "performed" differently across space and time. Indeed, the performative nature of gender has long been articulated by noted feminist theorists such as Judith Butler (1988) and by academics like West and Zimmerman (1987) in their seminal article titled "Doing Gender.” That gender is a social, cultural, and political construct, rather than an innate quality of a person's biological sex, results in several critical interrogations of the nature of gender performances and their effects on both women and men.

While not occluding the role of biology and its link to culture, gender can be said to be constituted through social interactions and as such serves as a "powerful ideological device, which produces, reproduces and legitimates choices" (West \& Zimmerman, 1987, p. 147). Although the broad area of "gender studies" incorporates a variety of different research 
streams, due to the historic and continued oppression of women within largely patriarchal societies, much of the academic discourse on gender has been developed and articulated through the lens of feminist scholarship (Aitchison, 2005; Hall, Swain, \& Kinnaird, 2003). Feminist scholarship is itself heterogenous and over time has become underpinned by varying philosophical conceptualizations of the nature of (masculinist) human (and nonhuman) existence, realities, interactions, and interconnections within the context of a complex social world. Many feminisms have therefore emerged but are generally clustered into what are termed in an historical sense as three "waves": feminist empiricism, standpoint feminism, and poststructural feminism (see, e.g., Code, 2000; Figueroa-Domecq, Pritchard, SegoviaPérez, Morgan, \& Villacé-Molinero, 2015, for further discussion of each of these waves). There have of course been many criticisms of this rather linear conceptualization of feminist thought as it seeks to suggest that there are no intersections or continuities between and among the various waves, that each wave represents an advancement on the previous one and importantly this historicity is quite specific to Western contexts (Browne, 2014).

Today it is recognized that there is no universal definition of feminism and the question that seems more pertinent is: For what purpose is feminist knowledge and scholarship? The aim of feminist theorizing is to achieve political and social change, not just in the conscious and material circumstances of women but also in the relationship between men and women in society, recognizing that they are inextricably linked as intimated in the quote from Marilyn Frye at the beginning of this introduction. That is, there is a fundamental political emancipatory project that underpins much of feminist scholarship. Yet, gender studies are often said to be about women's problems, thus failing to acknowledge the complex intersections between "men's and women's spaces and the dynamics of gender relations" (Kolawole, 2005, p. 251). Further, relations between men have been observed to be also gendered (Rotman \& Savulis, 2003). Therefore, it is surprising that issues of masculinity are often elided in tourism studies on gender (Pritchard, Morgan, Ateljevic, \& Harris, 2007), although a recent book by Thurnell-Read and Casey (2014) has sought to partially address this lacuna.
The leisure studies literature, which bears a strong family resemblance to tourism studies, has been exploring women's participation and constraints in leisure through significant empirical projects since the latter half of the 1970s (Aitchison, 2005). In 2013, Karla Henderson and Heather Gibson published an integrative review of research and publications on women and leisure (which synthesized four separate reviews they had undertaken from 1980 to 2010) and concluded that most of the studies used qualitative methods and could be divided into seven broad themes, including resistance and empowerment through leisure, feminist frameworks, family, psychical and mental health and social inclusion. However, in tourism studies, it is generally agreed that serious academic interrogations of gender emerged only in the early 1990s, much later than they did in other fields of study (Aitchison, 2005). Noted publications in the decade of the 1990s include the text by Kinnaird and Hall (1994) titled Tourism: A Gender Analysis, the article by Veijola and Jokinen (1994) on the "Body in Tourism," and the special issue of Annals of Tourism Research on "gender in tourism" edited by Swain (1995). In 2003 another special issue on tourism and gender appeared in the journal Tourism Recreation Research (Hall et al., 2003), which offered reflections on the "gender agenda" (p. 7) and concluded that "there is still much to debate and contest at the interface of gender and tourism to further our understanding of tourism processes" (p. 7).

More recently, Munar et al. (2015) published a report on the gender gap in tourism studies (which focused on key leadership indicators in the tourism academy including journal editorship) and concluded that women are underrepresented in leadership and gatekeeping positions. Figueroa-Domecq et al. (2015) undertook an exegesis of the "state of the art" of scholarship on tourism and gender and determined that while research in this area has increased in the last three decades, it remains marginal within the wider context of enquiry of and about tourism. In their review, they found that most of the research in this area adopted quantitative methodologies with the key topics grouped into four broad categories: gendered tourists, gendered hosts, gendered labor, and theory, research, and education. Importantly, they argue that gender 
research in tourism is "disarticulated from wider feminist and gender aware initiatives and lacks the critical mass of research leaders, publications, citations and multi-institutional networks which characterise other tourism sub-fields” (p. 87).

The continued failure of gender research in and about tourism to engage sufficiently with wider theoretical discussions taking place in other disciplines and fields of study is exemplified by the polemics surrounding women's rights and human rights. Gender research generally regards the struggle for women's rights as inseparable from the struggle for human rights. This notion is often articulated as “women's rights as human rights" but we have found no in-depth theorization of this link within the tourism literature. In an interesting and insightful discussion Nayak (2013) problematized the conceptualization of women's rights as human rights as either leading to an acceptance of a homogenizing universalism or cultural relativism. Nayak wrote that:

It is alleged that feminists calling for universal human rights base their claim to rights on a Western, white middle class women's perspective... cultural relativists charge that the essentialist position taken by many feminists is merely another instance of Western values and norms being imposed on non-Western countries in an imperialistic and neo-colonial manner. (pp. 85-86)

Studies that focus on the "liberation" and "empowerment" of women in the "Third World" through, for example, community-based tourism projects and written from the perspective of Western women researchers often fail to consider cultural and historical specificities and moreover do not often seek to unpack the colonial nature of developmental models. In this regard, Arnfred (2004) argued that one of the areas in which "colonial continuities are still alive and kicking is in gender and development discourse” (p. 11). She contends that in an African context, referring to "female subordination" is far too simplistic and generally misleading. However, these representations of African women as downtrodden and overworked "beasts of burden," as victims, provides legitimacy to "concerted Western efforts to come to their rescue" (p. 12). Although Arnfred admits that in gender and development discourse, the "victimization" of
African women is increasingly being questioned and criticized, this nevertheless fails to disrupt the continued persistence of the "othering" of African women.

According to Chandra Mohanty (1988), "universal images of the 'Third World woman' (the veiled woman, chaste virgin, etc) —images constructed from adding 'the Third World difference" to 'sexual difference'-are predicated upon (and hence bringing into sharper focus) assumptions about Western women as secular, liberated, and having control over their own lives" (p. 74). This dichotomous construction of "Third World" and Western women results in a process of "othering" of the former and fails to consider the possibility that the self can only be created by means of the other (Mohanty, 1988). Furthermore, in this simplistic binary characterization, the "Third World” woman lacks agency. Returning to Figueroa-Domecq et al.'s (2015) review of the current state of gender research in tourism, it is argued here that in keeping with much of the existing scholarship in tourism, tourism gender research is "heavily Anglo-centric," eliding the voices of those who do not write, research, or who do not have lived experiences in English. Indeed, in the tourism literature, little has been written on the experiences of women in Africa, the Caribbean, Latin America, Asia, and all the previously colonized territories from the perspective of the women themselves.

We go further to argue that tourism gender research has also failed to take sufficient account of the complex intersectionalities between gender and a host of identifications including race, class, sexuality, and age (as argued by poststructural feminists). Gender is but one value through which Western, white, bourgeois, heterosexual Man (what Haraway, 1991/2013, deems as "the master subject”) mediates power, but race, class, and sexual preference are also equally important (Rose, 1993). McGirr (2003) contends that "Man's hegemony is dependent upon ceaselessly excluding and marginalizing women, people of color and homosexuals" (p. 65). The term "intersectionality" was originally popularized by Kimberlé Crenshaw (1989), a noted black feminist, and referred to the way in which racial and sexual subordination were inextricably linked. An inability to understand the mutually reinforcing relationship between racism and sexism, Crenshaw argued, had led to the significant 
elision of black women's experiences from both the discourses of feminism and the discourses of antiracism.

However, the notion of intersectionality has since been extended to include the intersections between and among gender and a host of multiple identifications that go beyond race. Henderson and Gibson (2013), writing in the context of leisure studies, identified intersectionality as a "promising paradigm” (p. 115) for the future study of gender, women, and leisure. What underpins the notion of intersectionality is the idea that women are a heterogenous group and do not therefore have the same experiences of oppression. Intersectionality rejects essentialized views of women's experiences and the inherent power implications of such absolutism and instead embraces the pluralism and fluidity of identity categories. Haraway (2013), in advocating what she terms "cyborg feminism," stated this cogently thus:

None of 'us' have any longer the symbolic or material capability of dictating the shape of reality to any of 'them.' Or at least 'we' cannot claim innocence from practising such dominations. White woman, including socialist feminists, discovered (that is, were forced kicking and screaming to notice) the non-innocence of the category 'woman.' Cyborg feminists have to argue that 'we' do not want any more natural matrix of unity and that no construction is whole. (p. 157)

Still, although intersectionality is a useful paradigm it does have its detractors who argue that recognizing such multiple identifications is counterproductive to women's struggle for equality as it focuses on difference between and among women rather than their commonalities (chiefly common experiences of oppression in a male-dominated world) (see Nayak, 2013). Intersectionality, it is argued, serves to fracture the feminist project and weakens its political power to enable change for all women. Okin (1994, cited in Nayak, 2013) argued that while women from different cultural and social contexts might experience sexism differently, they still experience sexism. Haraway (2013) cautioned against "lapsing into boundless difference” (p. 160) and surrendering the job of making real, though partial, connections between and among women. For her part, Siegel (1997) argued that while it is difficult for third wave feminists to say "we" it is still vital to the success of the feminist political project. We argue in this introduction that recognizing the differences between and among women based on varied historical, cultural, social, and political contexts is crucial. There is no "one size fits all" in women's lived experiences nor in the development and implementation of strategies to enable women's empowerment. Adopting such a reductionist approach is, we believe, doomed to failure. And we do not see this perspective as inconsistent with a recognition of the common struggles that women still face. Women worldwide can work together without negating difference under an essentialist project that portends to speak for all women. Indeed, we agree with Friedman (1998), who contended that "to define identity solely in terms of gender reinscribes other forms of oppression by rendering them invisible" (p. 20). It is in this light that we argue for more gender and tourism research to reflect the diverse voices of women from and within Africa, Asia, Latin America, and the Caribbean, thus breaking the Euro/Anglocentric stranglehold of existing research in this, as in many other areas, of tourism scholarship.

In this special issue, Maliva, Bulkens, Peters, and van der Duim seek to do just that. Their research illustrates the extent to which Zanzibari women have agency over their own lives, disrupting traditional views of African women as victims. They draw on enactment theory to demonstrate how Zanzibari women in tourism can challenge, negotiate, and resist religious and cultural norms through entrepreneurial activities. In this account, Maliva et al. enable the voices of Zanzibari women to be heard as they narrate how they make sense of and influence their own environments to create employment opportunities for themselves in the tourism industry. It is in this process of sensemaking that new meanings and identities emerge for the women.

The contribution by Foley, Grabowski, Small, and Wearing focuses on women in villages on the Kokoda Track in Papua New Guinea and illustrates the way these women negotiate the power dynamics as they go about their day-to-day social interactions in the development of sustainable tourism microbusinesses. Foley et al. agree with our 
own previously articulated view about the need to understand differences in the lived experiences of women and claim in their article that "it is essential, to undertake research at the micro level that examines feminist issues in the context of specific groups of women to provide insight into practice and theoretical development not dominated by western-centric research.” They draw on insights from three theoretical perspectives to explore the issue of women's empowerment in the Kokoda villages: Michel Foucault's approach to governmentality, Chandra Mohanty's postcolonial feminist perspective, and Anthony Giddens' structuration theory. Using a participatory approach in which a series of workshops were held with women in the villages along the Kokoda track, the authors suggest that through the involvement by Kokoda women in a community-based ecotourism development project they have managed to resist not only the patriarchal structures of their communities, but also the dominant neoliberal capitalist construction of the tourism industry.

The gendered nature of employment is a key issue that has preoccupied gender and feminist studies for decades. Haraway (2013) borrowed from Richard Gordon's 1983 notion of the "homework economy" to explain how work was redefined as being "both literally female and feminized whether performed by men or women” (p. 166). This feminization of labor has serious implications as it exposes the vulnerability of jobs so ascribed, making them easily "dissassembled and reassembled" (p. 166). Further the remuneration and benefits assigned to jobs seen as "feminine" has traditionally been lower than those defined as "masculine." This is important for tourism as it has often been argued that the dependence of the tourism industry on human resources results in the creation of jobs that are low skilled, low paid, and part-time. These jobs are unsurprisingly often carried out by women, and within the tourism industry there has developed a culture of gendered employment that attributes certain job roles as being more appropriate to women (Jordan, 1997).

Sinclair (1997) argued that "work in tourism . . . is structured along gender lines and generally conforms to dominant gender norms” (p. 6). In their bibliometric analysis of full research papers published in indexed tourism journals between 1985 and 2012, Figueroa-Domecq et al. (2015) indicated that of the 466 papers analyzed, 59 of these dealt with gendered labor and of this total the majority (34) dealt with gender discrimination and occupational segregation. It is not clear how many of these papers focused on the non-English-speaking world but, given the overall dearth of published research in and of tourism that examines these cultural and geographical contexts, it would not be unreasonable to discern that the non-English-speaking world would be underrepresented in these analyses of gendered labor. Admittedly, we have seen a few recent publications that seek to explore gendered labor in non-English-speaking contexts in the developing world. For example, Guimarães and Silva (2016) explored the gender wage gap in the Brazilian tourism sector and concluded that there is still discrimination because women are less valued than men even when they perform the same job roles.

The contribution in this special issue by Bakas, Costa, Breda, and Durão draws on feminist economics to examine the gender wage gap in Portugal, considered a peripheral region of Western Europe. They argue there are several theories that seek to explain the gender wage gap but their article is different in so far as it adopts an interpretative approach, drawing on the narratives of research participants to explore the ways in which the gender wage gap is created and maintained. The results of their study reveal several factors that contributed to the gender pay gap in the Portuguese tourism industry, including horizontal segregation, the continued prominence of men in higher hierarchical positions, and women's apparent lack of both temporal and geographical flexibility. They conclude with several policy recommendations aimed at eliminating the gender pay gap.

Cultural geographers like Rose (1993) have argued that spaces are gendered. Public and private spaces (such as the home) are masculinized and feminized, respectively, and thus mirror the gendered power relationships that infuse our social world. Dowler, Carubia, and Szcygiel (2005) suggested feminist scholars have argued that landscape is a medium through which socially constructed "gender stereotyping is perpetuated" (p. 1). Interestingly, Dowler et al. deepened the discussion of 
gendered landscapes to include the moral dimension. They contended that:

\begin{abstract}
Historically landscapes have been exempted from moral responsibility due to their imagined nature ... it is evident in the early studies of landscape that there was literally a 'love' for the landscape. As the cultural turn has proven, this was certainly a blinded love, which was 'unseeing' of the landscape as an active system of oppression. (p. 3)
\end{abstract}

Dowler et al. (2005) emphasized this point by arguing that "landscapes are not innocent; rather they are the palette of a specific moral agenda" (p. 7) and suggested further that although much of the literature has focused on the moral landscape, insufficient explorations have been conducted on "the gendering of that morality" (p. 7). In tourism, this concept of the gendered identity of landscape was adapted by Pritchard and Morgan (2000), who argued that representations of tourist destinations (e.g., in promotional materials) manifest the gendered nature of landscapes. In a very general sense they suggested that those landscapes in the south and east of the world were represented as feminine and sexualized. However, hostile environments in the north were portrayed as masculine, bleak, and rugged. Pritchard and Morgan surmised that:

In contrast to the passive, seductive, feminine landscapes of the south and east, northern male landscapes are active, wild, untamed and often harsh and even penetrative. Moreover, these wild landscapes are exclusively oriented towards the male tourist gaze. (p. 897)

Two of the articles in this special issue draw insights from this notion of gendered landscapes. Yudina, Grimwood, Berbary, and Mair focus on the way in which the representation of a nature-based arctic tourism destination (Churchill, Manitoba in British Columbia) reproduces dominant gender stereotypes not only of the landscape itself (as an imagined object) but also of the polar bears (nonhuman subjects) that inhabit this landscape. Using critical discourse analysis of promotional texts, they reveal "how various representations of polar bear tourism impose hegemonic gender roles onto polar bear bodies, which are emplaced within a conventionally gendered landscape.” Importantly, they expose the power relationships inherent in these gendered representations of the arctic landscape, the polar bears and the polar bear/human relationships that result in certain tourism practices. They argue for a questioning of these taken for granted gendered representations so that spaces can be created in tourism for more equitable practices.

In their contribution, Cassel and Pashkevich also explore arctic landscapes but this time the geographical context shifts to Russia. Focusing on the Nenets Autonomous District, they use a mix of qualitative methods (semistructured interviews, observation, and analysis of online tourism promotional materials) to explore hegemonic masculinist representations of the north and how these both "inform and are challenged by tourism and its representations and practices.” They indicate that among these representations is that of the artic as being a demanding and risky playground, largely the domain of the "macho" male. Unsurprisingly, risk-taking is associated with masculinity, and women are normally represented as involved in more sedate activities traditionally associated with the private space of the home (such as cooking). Recently, Yang, KhooLattimore, and Arcodia (2016) undertook a systematic literature review of risk and gender research in tourism and defined risk itself as being gendered. For example, women's risk taking behavior is likely to be evaluated in a more negative way than men's as the latter is "associated with the construction of masculinity, whereas risk aversion is a desirable value of femininity" (p. 89). This gendered representation of risk is certainly evident in the practices and performances of men and women in their tourism activities in the Russian arctic, as illustrated in Cassel and Pashkevich's contribution in this special issue. However, their research has identified a nascent challenge to these gendered portrayals of these arctic landscapes and tourism performances, through the involvement of men in domesticated activities such as cooking and caring for customers. They caution though that although this is a "sign of potential transformation" it is only partial and has not to date served to disrupt the hegemony of masculinist portrayals of, and performances within, the Russian arctic tourism landscape.

In summary, the five article in this special issue have contributed to the critical conversations that we 
urgently need to engage with in order to understand the nature of gender relationships in tourism. They have inspired us to think about gender from different theoretical perspectives and from diverse geographical contexts, including the often neglected Third World. In our deliberations on the relationship between gender and tourism we need to remind ourselves that research is not value neutral. Indeed, the term “passionate scholarship” according to Morley (1996) "breaches the academic rule of disembodiment” (p. 128), and as such we firmly locate ourselves in the context of critical tourism scholarship that has long ago gone beyond any notion of value neutral research. Our focus on gender and tourism mirrors our own positionality as women in tourism, and the articles in this special issue reflect the sort of theorizing that we feel is central to critical tourism scholarship.

\section{References}

Aitchison, C. (2005). Feminist and gender perspectives in tourism studies: The social-cultural nexus of critical and cultural theories, Tourist Studies, 5(3), 207-224.

Arnfred, S. (2004). Introduction: Re-thinking sexualities in Africa. In S. Arnfred (Ed.), Re-thinking sexualities in Africa (pp. 7-29). Uppsala, Sweden: Almqvist Wiksell Tryckeri AB.

Browne, V. (2014). Introduction: Feminism and historical time. In V. Browne (Ed.), Feminism, time and non-linear history (pp. 1-23). New York, NY: Palgrave MacMillan.

Butler, J. (1988). Performative acts and gender constitution: an essay in phenomenology and feminist theory. Theatre Journal, 40(4), 519-531.

Code, L. (Ed.). (2000). Encyclopaedia of feminist theories. New York, NY: Routledge.

Crenshaw, K. (1989). Demarginalizing the intersection of race and sex: A black feminist critique of antidiscrimination doctrine, feminist theory and antiracist politics. University of Chicago Legal Forum, 1(8), 139-167.

Dowler, L., Carubia, J., \& Szcygiel, B. (2005). Gender and landscape: Renegotiating the moral landscape. London, UK: Routledge.

Figueroa-Domecq, C., Pritchard, A., Segovia-Pérez, M., Morgan, N., \& Villacé-Molinero, T. (2015). Tourism gender research: A critical accounting. Annals of Tourism Research, 52, 87-103.

Friedman, S. (1998). Mappings: Feminism and the cultural geographies of encounter. Princeton, NJ: Princeton University Press.

Guimarães, C., \& Silva, J. R. (2016). Pay gap by gender in the tourism industry of Brazil. Tourism Management, 52, $440-450$.
Hall, D., Swain, M., \& Kinnaird, V. (2003). Tourism and gender: An evolving agenda. Tourism Recreation Research, 28(2), 7-11.

Haraway, D. (2013). Simians, cyborgs, and women: The reinvention of nature. London, UK: Routledge. (Original publication 1991)

Henderson, K., \& Gibson, H. (2013). An integrative review of women, gender and leisure: Increasing complexities. Journal of Leisure Research, 45(2), 115-135.

Jordan, F. (1997). An occupational hazard? Sex segregation in tourism employment. Tourism Management, 18(8), 525-534.

Kinnaird, V., \& Hall, D. (1994). Tourism: A gender analysis. Chichester, UK: John Wiley.

Kolawole, M. (2005). Re-conceptualizing African gender theory: Feminism, womanism and the Arere metaphor. In S. Arnfred (Ed.), Re-thinking sexualities in Africa (pp. 251-268). Uppsala, Sweden: Nordic Africa Institute.

McGirr, P. (2003). The Vietnam veterans' memorial: Landscape and gender in the twentieth century. In D. L. Rotman \& E-R. Savulis (Eds.), Shared spaces and divided places: Material dimensions of gender relations and the American historical landscape (pp. 62-85). Knoxville, TN: University of Tennessee Press.

Mohanty, C. (1988). Under Western eyes: Feminist scholarship and colonial discourses. Feminist Review, 80, 61-88.

Morley, L. (1996). Interrogating patriarchy: The challenges of feminist research. In L. Morley \& V. Walsh (Eds.), Breaking boundaries: Women in higher education (pp. 128-143). Bristol, UK: Taylor and Francis.

Munar, A. M., Biran, A., Budeanu, A., Caton, K., Chambers, D., Dredge, D., Gyimóthy, S., Jamal, T., . . . Ram, Y. (2015). The gender gap in the tourism academy: Statistics and indicators of gender equality. Copenhagen, Denmark: While Waiting for the Dawn.

Nayak, B. S. (2013). Challenges of cultural relativism and the future of feminist universalism. Journal of Politics and Law, 6(2), 83-89.

Pritchard, A., \& Morgan, N. (2000). Privileging the male gaze: Gendered tourism landscapes. Annals of Tourism Research, 27(4), 884-905.

Pritchard, A., Morgan, N., Ateljevic, I., \& Harris, C. (2007). Tourism and gender: Embodiment, sensuality and experience. Wallingford, UK: CABI.

Rose, G. (1993). Feminism and geography. Minneapolis, MN: University of Minnesota Press.

Rotman, D. L., \& Savulis, E-R. (Eds.). (2003). Shared spaces and divided places: Material dimensions of gender relations and the American historical landscape. Knoxville, TN: University of Tennessee Press.

Siegel, D. (1997). Reading between the waves: Feminist historiography in a 'postfeminist' moment. In L. Heywood \& J. Drake (Eds.), Third wave agenda: Being feminist: Doing feminism (pp. 55-82). Minneapolis, MN: University of Minnesota Press. 
Sinclair, M. T. (Ed.). (1997). Gender, work and tourism. London, UK: Routledge.

Swain, M. B. (1995). Introduction: Gender in tourism. Annals of Tourism Research, 22(2), 247-266.

Thurnell-Reid, T., \& Casey, M. (Eds.). (2014). Men, masculinities, travel and tourism. New York, NY: Palgrave MacMillan.

Veijola, S. \& Jokinen, E. (1994). The body in tourism. Theory, Culture and Society, 11, 125-151.

West, C., \& Zimmerman, D-H. (1987). Doing gender. Gender and Society, 1(2), 125-151.
World Economic Forum. (2016). The global gender gap report. Geneva: Switzerland: Author.

World Health Organization. (2015). Gender. Fact Sheet No 40.3 Retrieved from http://www.who.int/mediacentre/ factsheets/fs403/en/

Yang, E. C. L., Khoo-Lattimore, C., \& Arcodia, C. (2016). A systematic literature review of risk and gender research in tourism. Tourism Management, 58, 89-100. 